\title{
Effects of thermomechanical history and environment on the fatigue behavior of $(\beta)$-Ti-Nb implant alloys
}

\author{
André Reck ${ }^{1 *}$, Stefan Pilz ${ }^{1,3}$, Ulrich Thormann ${ }^{2}$, Volker Alt $^{2}$, Annett Gebert ${ }^{3}$, Mariana Calin $^{3}$, Christian Hei ${ }^{2}$, and \\ Martina Zimmermann ${ }^{1}$ \\ ${ }^{1}$ Technical University Dresden, 01062 Dresden, Germany \\ ${ }^{2}$ University Hospital Gießen-Marburg GmbH, 35385 Gießen, Germany \\ ${ }^{3}$ Leibniz Institute for Solid State and Materials Research, 01062 Dresden, Germany
}

\begin{abstract}
This study examined the fatigue properties of a newly developed cast and thermomechanical processed $(\beta)-\mathrm{Ti}-40 \mathrm{Nb}$ alloy for a possible application as biomedical alloy due to exceptional low Young's modulus (64-73 GPa), high corrosion resistance and ductility (20-26\%). Focusing on the influence of two microstructural states with fully recrystallized $\beta$-grain structure as well as an aged condition with nanometer-sized $\omega$-precipitates, tension-compression fatigue tests $(\mathrm{R}=-1)$ were carried out under lab-air and showed significant differences depending on the $\beta$-phase stability under cyclic loading. Present $\omega$ precipitates stabilized the $\beta$-phase against martensitic $\alpha$ " phase transformations leading to an increased fatigue limit of $288 \mathrm{MPa}$ compared to the recrystallized state $(225 \mathrm{MPa})$, where mechanical polishing and subsequent cyclic loading led to formation of $\alpha$ "-phase due to the metastability of the $\beta$-phase. Additional studied commercially available $(\beta)-\mathrm{Ti}-45 \mathrm{Nb}$ alloy revealed slightly higher fatigue strength $(300 \mathrm{MPa})$ and suggest a change in the dominating cyclic deformation mechanisms according to the sensitive dependence on the $\mathrm{Nb}$-content. Further tests in simulated body fluid (SBF) at $37^{\circ} \mathrm{C}$ showed no decrease in fatigue strength due to the effect of corrosion and prove the excellent corrosion fatigue resistance of this alloy type under given test conditions.
\end{abstract}

\section{Introduction}

In the last two decades intensive research was carried out to develop new titanium alloys for the use as implant materials [1-4].

Focus of this research efforts were mostly B-titanium alloys, since they show the lowest Young's modulus compared to $\alpha$ and $(\alpha+\beta)$ alloys while providing the possibility to a significant stiffness reduction due to tailored composition and thermomechanical treatment. Major advantage of these properties is the minimization of "stress shielding effects", which can lead to bone atrophy, impaired healing and consequently premature failure or loosening of implants due to the high difference of Young's moduli compared to the cortical bone (10-30 GPa) [1-2,5-8]. This is particularly important in case of implants for osteoporotic bones, which have a lower mass and density then the healthy bone and consequently an even more reduced stiffness corresponding to elastic modulus values $<10 \mathrm{GPa}$ [9].

The primary challenge is to maintain excellent static and cyclic strength while providing an alloy with lowest possible Young's modulus $[1,10]$. The fatigue behavior of new $\beta$-titanium alloys with low stiffness is therefore of central relevance, especially under the effects of corrosion [11-14]. Thus, many strengthening strategies involving diverse thermomechanical treatment strategies to positively influence the fatigue strength were in focus of research. Whereas work hardening for instance increases the static strength, fatigue strength remains mostly unaltered [15-24]. The most significant effect in case of TiNb-based alloys seems to be possible due to precipitation and grain boundary hardening in order to effectively hinder dislocations to move through the material and thus, positively influence the fatigue limit $[16,18]$.

Another way to improve the fatigue strength is particle dispersion (e.g. yttrium oxide, titanium boride) in the matrix of these alloys or increasing the oxygen content [25-29].

Precipitation of hexagonal omega $(\omega)$-phase is another promising approach and proved to be enhancing the fatigue strength of TNTZ [30]. Detrimental effects with higher volume content of $\omega$-phase are an increase in Young's modulus as well as lower ductility due to the brittle nature of this phase. Consequently the content, distribution and size of the $\omega$-precipitates have to be well under control with aging time and temperature depending on the exact alloy composition. Whereas TiNb-based $\beta$-titanium alloys without $\omega$-phase show, determined by the exact alloy composition, the e/a

Corresponding author: andre.reck@tu-dresden.de 
relation and the bond order (Bo value)/d-electron-orbital energy level (Md value), typical stress-induced $\alpha$ ' -phase formation as well as mechanical twinning, present isothermal or athermal $\omega$-precipitations influence these features to great extent [31-33]. Moreover, diverse features like stress-induced $\omega$-bands and "dislocation channels" depleted on $\omega$-precipitations can be part of the deformation process, which was studied by Lai et al. in gum metal [34]. The additional sensitive dependence on the $\mathrm{Nb}$-content and thus $\beta$-phase stability at room temperature $[32,35]$ combined with changed deformation features made TiNb-based $\beta$-titanium alloys to very promising but also very complex implant materials, whose successful application is particularly determined by the fatigue properties and cyclic deformation behaviour.

Hence, this study aims at the identification of differences in S-N based fatigue properties of a binary $(\beta)-\mathrm{Ti}-40(\mathrm{wt} \%) \mathrm{Nb}$ alloy with and without isothermal $\omega$ precipitations. Comparisons will be drawn to a previous study focusing on the notch effect due to an industrial surface condition of the same alloy [36]. Furthermore commercially available $(\beta)-\mathrm{Ti}-45(\mathrm{wt} \%) \mathrm{Nb}$ was studied to comprehend influences of $\mathrm{Nb}$-content and first invitro tests are carried out to assess corrosion fatigue.

\section{Experimental methods}

\subsection{Alloy processing and machining}

All samples of $\mathrm{Ti}-40(\mathrm{wt} \%) \mathrm{Nb}$ were produced through a two-step casting process consisting of arc melting of the pure elements cp2-Ti $(99,7 \%)$ and $\mathrm{Nb}(99,9 \%)$ in highly purified argon followed by remelting via induction heating of the pre-alloys and casting into a cylindrical water-cooled $\mathrm{Cu}$ mold. Additional remelting steps were carried out to ensure the homogeneity of the $\beta$-titanium alloy.

Solution heat treatment $(1273 \mathrm{~K}, 24 \mathrm{~h})$ of the as-cast rods was carried out to resolve possible microsegregations followed by water quenching. In order to achieve a sheet form for further processing as well as grain refinement and work hardening, the rods were coldrolled in several steps to a final thickness reduction of $93 \%\left(\phi_{\text {total }}=2.66\right)$. Recrystallization $(1073 \mathrm{~K}, 20 \mathrm{~min})$ was executed between cold-rolling and at the end of the thermomechanical treatment. $(\beta)-\mathrm{Ti}-40 \mathrm{Nb}$ samples with $\omega$-phase were additionally aged at $573 \mathrm{~K}$ for $4 \mathrm{~h}$ to get a controlled precipitation of nanometer-sized $\omega$-particles in the $\beta$-matrix. Further details of the alloy processing can be found in our previous studies $[16,35]$.

The investigated $(\beta)-\mathrm{Ti}-45(\mathrm{wt} \%) \mathrm{Nb}$ alloy was bought in rod form with a diameter of $15 \mathrm{~mm}$ from MetSuisse Distribution AG and processed in the USA of ATI Specialty Alloys \& Components.

In preparation for the fatigue tests all studied samples were furthermore machined according to the geometries in Fig.1. ( $\beta$ )-Ti-40Nb sheet samples were laser-cut in agreement with our previous study [36]. Recrystallized samples, afterwards called Ti-40Nb-Rk, and aged samples with omega $\omega$-precipitations, afterwards called Ti-40Nb-Om4h were subsequently stepwise mechanically polished (Grit 2500) to remove the thin oxide layer from the heat treatment and to minimize surface roughness related notch influences and the heat affected zone (HAZ)) from the laser cutting [36]. ( $\beta$ )-Ti-45Nb rods were turned to the given geometry (Fig 1b) and also mechanically polished to Grit 2500.
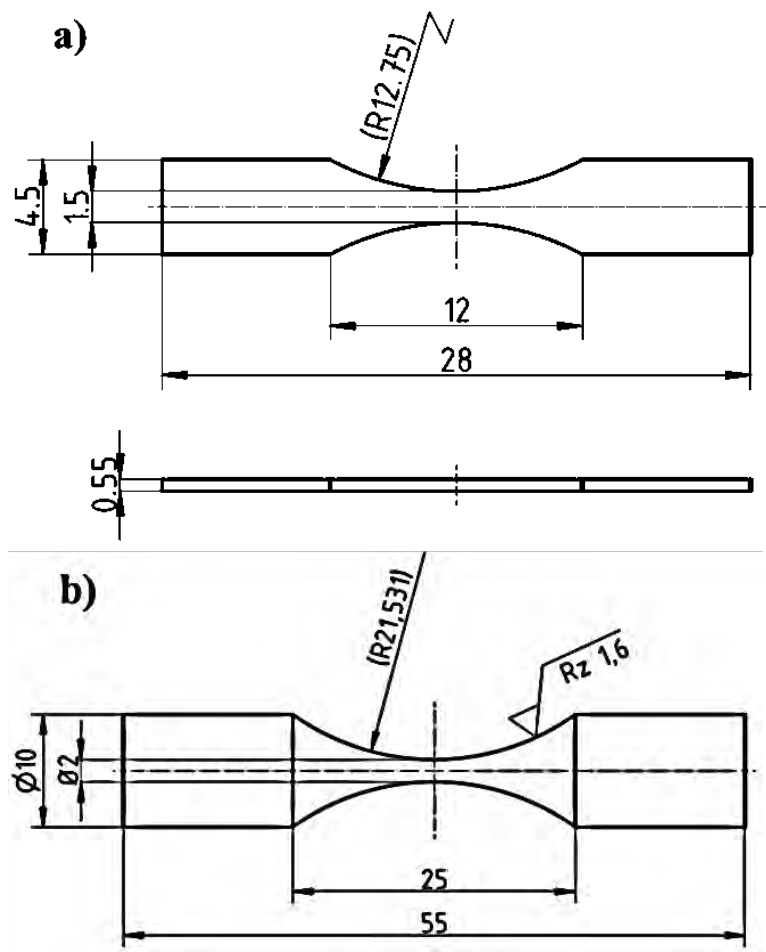

Fig. 1. a) Fatigue sample geometry ( $\beta$ )-Ti-40Nb; b) Fatigue sample geometry $(\beta)-\mathrm{Ti}-45 \mathrm{Nb}$

\subsection{Static and Fatigue tests}

After processing and machining of the samples, uniaxial tensile tests on $(\beta)-\mathrm{Ti}-40 \mathrm{Nb}$ were conducted to assess fundamental effects in the static behavior due to aging. Known values of industrial $(\beta)-\mathrm{Ti}-45 \mathrm{Nb}$ were obtained from the datasheet of the manufacturer. Load-controlled tension-compression $(\mathrm{R}=-1)$ fatigue investigations were carried out subsequently.

A servo-electric test system (Thelkin) was used for the fatigue study. All tests at laboratory air were executed at $20 \mathrm{~Hz}$ after carefully adjusting the test system control parameters. These parameters regulate, depending on the stiffness and the strength of the samples, the vibration behaviour (optimal sinus curve) of the tested material.

To assess the fatigue range of the material loadincrease tests were carried out followed by regular single-step tests on 3 to 4 stress levels each with 2 to 4 samples for each tested condition.

Most of the investigations were realized in lab-air under pressurized air cooling. The $(\beta)-\mathrm{Ti}-45 \mathrm{Nb}$ were additionally studied in simulated body fluid (SBF) to evaluate the possible influence of corrosion fatigue. The developed set-up is depicted in Fig.2. A built in heating plate holds the test temperature at a constant temperature of $310 \mathrm{~K} \pm 2 \mathrm{~K}\left(37^{\circ} \mathrm{C}\right)$. Ringer's solution consisting of a mixture of different chlorides (Tab.1) was used as SBF. 
Sample mass was measured before and after the fatigue tests. Frequency adjustment to $10 \mathrm{~Hz}$ was necessary to obtain stable sinus-curve testing under in-vitro conditions.

Table 1. Composition of Ringer's solution for in-vitro tests

\begin{tabular}{|c|c|c|c|c|c|}
\hline Component & $\mathrm{NaCl}$ & $\mathrm{KCl}$ & $\mathrm{CaCl}_{2}$ & $\mathrm{NaHCO}_{3}$ & $\begin{array}{c}\text { Dest. } \\
\mathrm{H}_{2} \mathrm{O}\end{array}$ \\
\hline Content in g/l & 8 & 0.2 & 0.2 & 1 & - \\
\hline
\end{tabular}

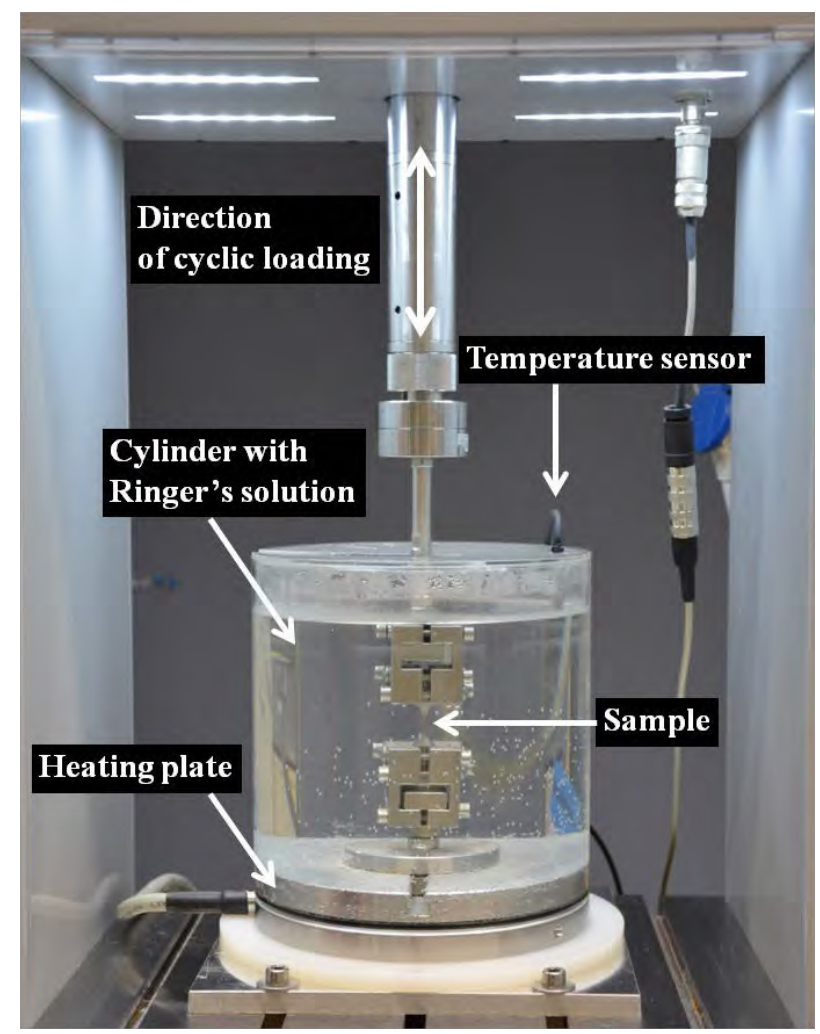

Fig. 2. In-vitro fatigue test set-up on Thelkin system

\subsection{Analytical investigations}

Before and after the fatigue tests different analytical methods were used.

The microstructure before cyclic loading was assessed with light and high-resolution electron microscopy. The high metastable character, especially of the recrystallized samples (Ti-40Nb_Rk) could be origin of possible phase transformation due to laser cutting or mechanical polishing.

XRD-measurements were executed after the processing of $(\beta)-\mathrm{Ti}-40 \mathrm{Nb}$ and TEM investigations were carried out to establish an understanding of the size and distribution of the $\omega$-precipitations. After the fatigue tests detailed fractographic analysis was conducted to identify crack origin and important characteristics of fatigue failure.

\section{Results and discussion}

\subsection{Microstructure and phase investigations}

The microstructural condition before the fatigue tests but after the laser cutting and subsequently mechanical polishing steps of the Ti-40Nb_Rk samples is depicted in Fig. 3.

Compared to the initial microstructure immediately after the thermomechanical treatment with single $(\beta)$ grain structure, local phase transformation can clearly be identified. A higher magnification of the light microscopy investigations reveals formation of $\alpha$ "'phase during the preparation of the samples. Either local heat development during laser processing or applied residual compression stresses from the mechanical polishing could result in the activation of the phase transformation, due to the high metastable character of this alloy condition. Special relevance obtains this result considering the high importance of laser processing for implant materials in automatized industrial process chains [36].

The aged Ti-40Nb_Om4h samples are on the contrary free of $\alpha$ "'-phase after the processing and preparation steps and consist only of $\beta$-phase and $\omega$ precipitates with an intermediate size of around $10 \mathrm{~nm}$, which are not present in the $\mathrm{Ti}-40 \mathrm{Nb} \mathrm{Rk}$ samples. Hence, it appears that the isothermal precipitates operate as stabilizer for the metastable $\beta$-matrix against phase transformations at a $\mathrm{Nb}$-content of $40 \mathrm{wt} \%$.

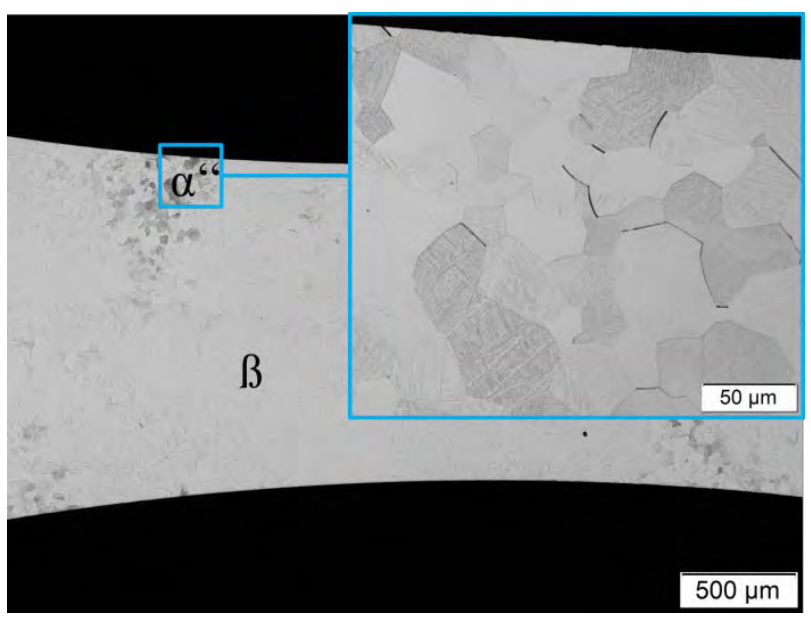

Fig. 3. Condition of Ti-40Nb Rk samples before fatigue loading (light microscopy): Local stress-induced $\alpha$ "-phase transformation due to laser cutting and preparation 

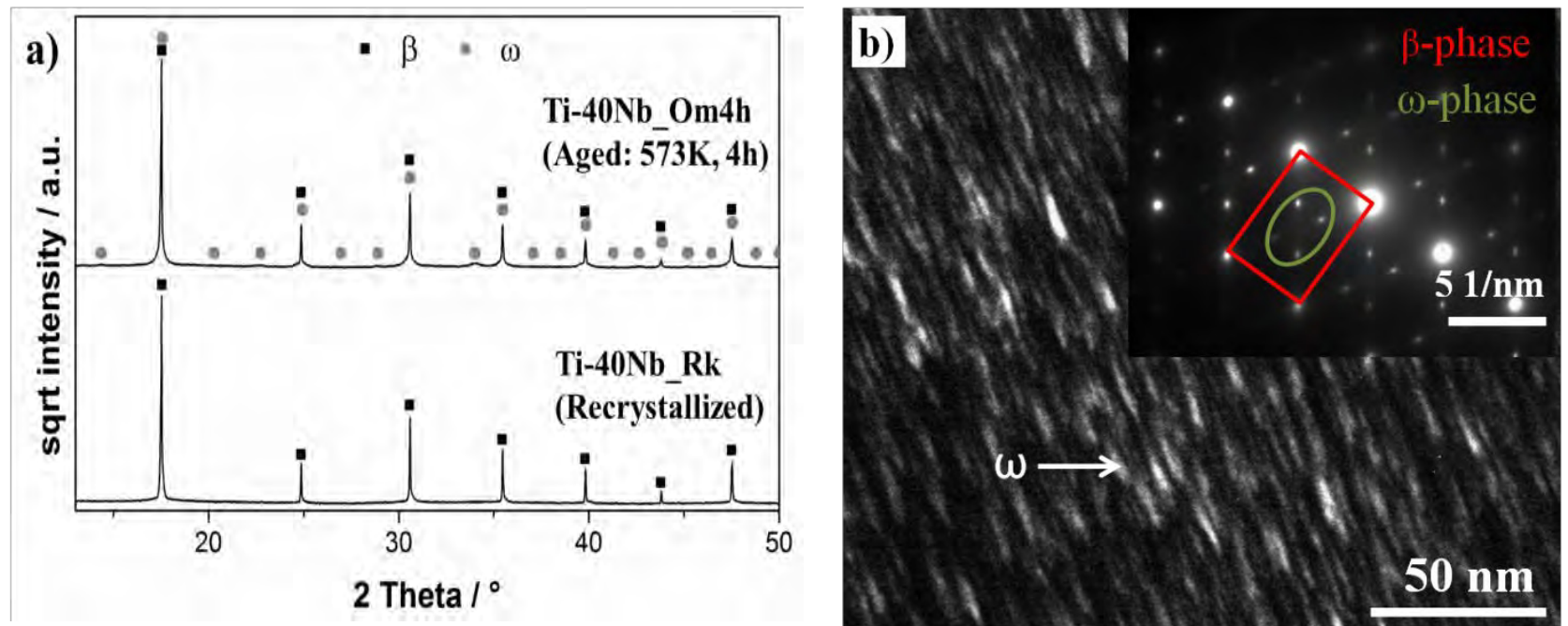

Fig. 4. a) XRD-analysis of Ti-40Nb after thermomechanical processing; b) Dark-field TEM image of isothermal ( $\omega$ )-precipitates after aging $(573 \mathrm{~K}, 4 \mathrm{~h})$ in the Ti-40Nb_Om4h samples

The major reason for the higher stability of the $\beta$-phase is most likely a further reduction of the martensitic finish temperature $\left(\mathrm{M}_{\mathrm{f}}\right)$ below room temperature due to the presence of the $\omega$-phase, which normally is valid for binary $\mathrm{Ti}-\mathrm{Nb}$ alloys over $42 \mathrm{wt} \% \mathrm{Nb}$ [31]. In addition to the higher stability of the $\beta$-phase, the presence of the $\omega$ phase also suppresses superelasticity and shape memory effects in the Ti-40Nb alloys, as could be observed in the recrystallized Ti-40Nb_Rk samples (Fig. 3) without $\omega$ phase [31-32].

Results of the XRD-analysis as well as the TEMinvestigation of the aged condition (Ti-40Nb_Om4h) are shown in Fig. 4. The XRD plot exhibits weak but distinct additional peaks of $\omega$-phase. The close structural relationship of the $\omega$ - and the $\beta$-phase results in a high similarity of their diffraction patterns and an overlap of the $\beta$-reflections with reflections of the $\omega$-phase. The slightly lower intensity of the $\beta$-peaks in the aged condition is however another effect due to the presence of the isothermal $\omega$-precipitates and an indication for slight texture changes after the aging treatment [30].

The dark field TEM image (Fig. 4b) shows the homogeneous distribution and size of the hexagonal $\omega$ phase. Distortion effects can thereby assigned to possible preparation effects caused by focused ion beam (FIB). Analyses reveals that the $\omega$ - phase is oriented to $\beta$ after the common relationship $[111]_{\beta} / /[0001]_{\omega}$ and four variants are presented by four reflections in the TEMdiffraction pattern. One reflection is particularly strong, whereas the neighbour reflection is almost undetectable (marked in Fig. 4b), which is typically proof for the preferred precipitation of a distinct variant [37]. Similar results are found e.g. by Nakai et al. in aged TNTZ [30].

The commercially available $(\beta)-\mathrm{Ti}-45(\mathrm{wt} \%) \mathrm{Nb}$ alloy shows compared to the thermomechanically treated $(\beta)$ $\mathrm{Ti}-40 \mathrm{Nb}$ alloy a single $\beta$-grain structure with linear segregations of $\alpha$ ''-phase (not depicted). This feature is distributed alongside the studied rod and very likely caused due to the extrusion process during manufacturing.

From the standpoint of phase stability and the relevant Bo-Md-diagram for this binary alloy with 45 $w t \% \mathrm{Nb}$ only $\beta$-phase should be present at room temperature [32,34]. However, an inhomogeneous alloy microstructure is present, which might influence the fatigue behaviour, e.g. crack initiation from microstructural barriers (e.g. $\alpha$ "- $\beta$ phase or grain boundaries) or defects at the interior of the material [38].

\subsection{Mechanical behavior}

\subsubsection{Static properties}

The mechanical properties of the alloys studied under static load are summarized in Table 2. All alloys show similar low Young's moduli between 62-73 GPa, which is favourable to minimize "stress-shielding", but show very different strength and ductility values.

A significant precipitation hardening effect can be identified in the aged $\mathrm{Ti}-40 \mathrm{Nb} \mathrm{Om} 4 \mathrm{~h}$ samples due to the nucleation and growth of isothermal $\omega$-precipitates compared to the recrystallized Ti- $40 \mathrm{Nb}$ Rk samples. Associated with that is on the one hand the slight increase in Young's modulus to $73 \mathrm{GPa}$ and the decrease of ductility due to the brittle nature of $\omega$. At the same time an increase in ultimate tensile strength up to 718 MPa can be observed.

Table 2. Static mechanical properties of the investigated alloys

\begin{tabular}{|c|c|c|c|c|}
\hline Alloy & $\begin{array}{c}\mathrm{E} / \\
\mathrm{GPa}\end{array}$ & $\begin{array}{c}\sigma_{0.2 \mathrm{PS}} / \\
\mathrm{MPa}\end{array}$ & $\begin{array}{c}\sigma_{\mathrm{UTS}} / \\
\mathrm{MPa}\end{array}$ & $\begin{array}{c}\mathrm{El} / \\
\%\end{array}$ \\
\hline Ti-40Nb_Rk & 64 & 315 & 498 & 26 \\
\hline Ti-40Nb_Om4h & 73 & 639 & 718 & 19.7 \\
\hline Ti-45Nb [39] & 62 & 475 & 503 & 34 \\
\hline
\end{tabular}


An acceptable compromise between static strength and low Young's modulus can be achieved by careful adjustment of the aging parameters. In the given study this was the case for an aging for $4 \mathrm{~h}$ at $573 \mathrm{~K}$, thus limiting the size and volume fraction of the $\omega$-phase. In addition, the typical "double-yielding" phenomenon caused by the stress-induced $\alpha$ "-transformation, which could be observed for the Ti- $40 \mathrm{Nb}$ _Rk samples, is almost fully suppressed in the aged condition. The $\beta$ matrix is consequently effectively stabilized and strengthened with the presence of $\omega$-phase in form of isothermal $\omega$-precipitates.

The static strength of the commercially available $(\beta)$ Ti-45Nb alloy depicted in Table 2 shows an intermediate value with very high ductility and low Young's modulus, although direct comparison to the self-processed $(\beta)$-Ti$40 \mathrm{Nb}$ is limited mainly due to the influence of the different sample geometries. However, without the $\omega$ phase the slightly higher $\mathrm{Nb}$-content shifts this alloy to a more stable character, due to the sensitive dependence of the mechanical behaviour of binary $\mathrm{Ti}-\mathrm{Nb}$ alloys on its chemical composition $[31,34,40]$.

\subsubsection{Fatigue results}

The fatigue properties of the two studied Ti-40Nb conditions are depicted in Fig. 5.

Whereas the recrystallized state (Ti-40Nb_Rk) shows a tension-compression fatigue limit of $\sigma_{\mathrm{a}}=\overline{225} \mathrm{MPa}$ at $2 \times 10^{6}$ cycles, the aged condition with present $\omega$-precipitations has a superior fatigue strength of around $\sigma_{\mathrm{a}}=$ $288 \mathrm{MPa}$. Since both heat treatment conditions were tested with the same mechanically polished surface and the same $\mathrm{Nb}$-content of $40 \mathrm{wt} \%$ this is a clear indication of the effectiveness of the additional aging treatment. The precipitation hardening on the basis of the $\omega$-phase proves to be an important factor regarding the successful application of $\mathrm{Ti}-40 \mathrm{Nb}$ as implant material. The improved mechanical properties of $\mathrm{Ti}-40 \mathrm{Nb}$ are in accordance with other studies on aged TNTZ and other dispersion strengthened TiNb-based alloys [28-30]. The relatively pronounced scatter of the fatigue results is caused by the inhomogeneous local formation of $\alpha$ "'-phase in the Ti40Nb_Rk samples (Fig. 3). Moreover, it has to be mentioned that due to the high degree of cold-rolling $\left(\phi_{\text {total }}=2.66\right)$ and the subsequent heat treatment a minimal bending load due to a slight uneven surface of the Ti-40Nb_Om4h samples could not be completely ruled out.

Comparing the results presented in Fig. 3 with results of a previous study of Ti- $40 \mathrm{Nb}-\mathrm{Rk}$ samples with the same geometry and test conditions [36] but with laser cut surface a remarkable increase of fatigue strength from $\sigma_{\mathrm{a}}=150 \mathrm{MPa}$ (laser cut surface) to $\sigma_{\mathrm{a}}=225 \mathrm{MPa}$ (mechanically polished surface) is apparent. The effect introduced by the laser cut surface can be determined by a notch factor $\mathrm{K}_{\mathrm{f}}$ of 1.5 .

Fig. 6 shows the fatigue results for the $(\beta)-\mathrm{Ti}-45 \mathrm{Nb}$ alloy in lab-air as well as in Ringer's solution as simulated body fluid. The cyclic strength of both test conditions is comparable and no significant decrease due to the influence of corrosion is detectable leading to a fatigue limit of $\sigma_{\mathrm{a}}=300 \mathrm{MPa}$ at $2 \times 10^{6}$ cycles.

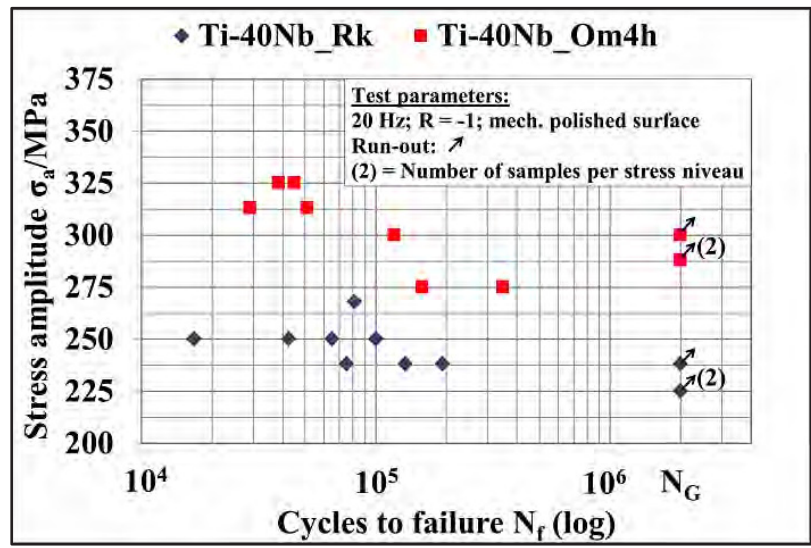

Fig. 5. Fatigue results of ( $\beta$ )-Ti-40Nb samples in the recrystallized (Ti-40Nb_Rk) and aged (Ti-40Nb_Om4h) condition

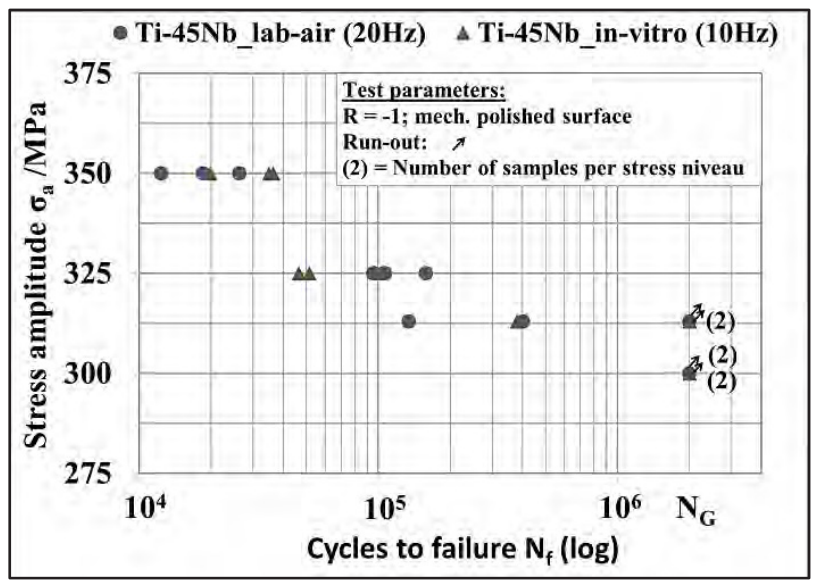

Fig. 6. Fatigue results of ( $\beta)-\mathrm{Ti}-45 \mathrm{Nb}$ samples tested in lab-air and in-vitro in Ringer's solution

Mass difference before and after the fatigue tests did not give any evidence of corrosion effects. Visual inspection in SEM and light microscopy also showed that no corrosion developed during fatigue testing proving the already studied excellent corrosion resistance of $(\beta)$-Ti$45 \mathrm{Nb}[13,41]$.

A direct comparison of $(\beta)-\mathrm{Ti}-45 \mathrm{Nb}$ with the recrystallized and aged condition of the $(\beta)-\mathrm{Ti}-40 \mathrm{Nb}$ alloy is restricted due to the difference in sample geometry, however a slightly superior fatigue strength of $(\beta)$-Ti$45 \mathrm{Nb}$ is undeniable, even considering the effect of precipi-tation hardening in $\mathrm{Ti}-40 \mathrm{Nb} \_\mathrm{Om} 4 \mathrm{~h}$. 


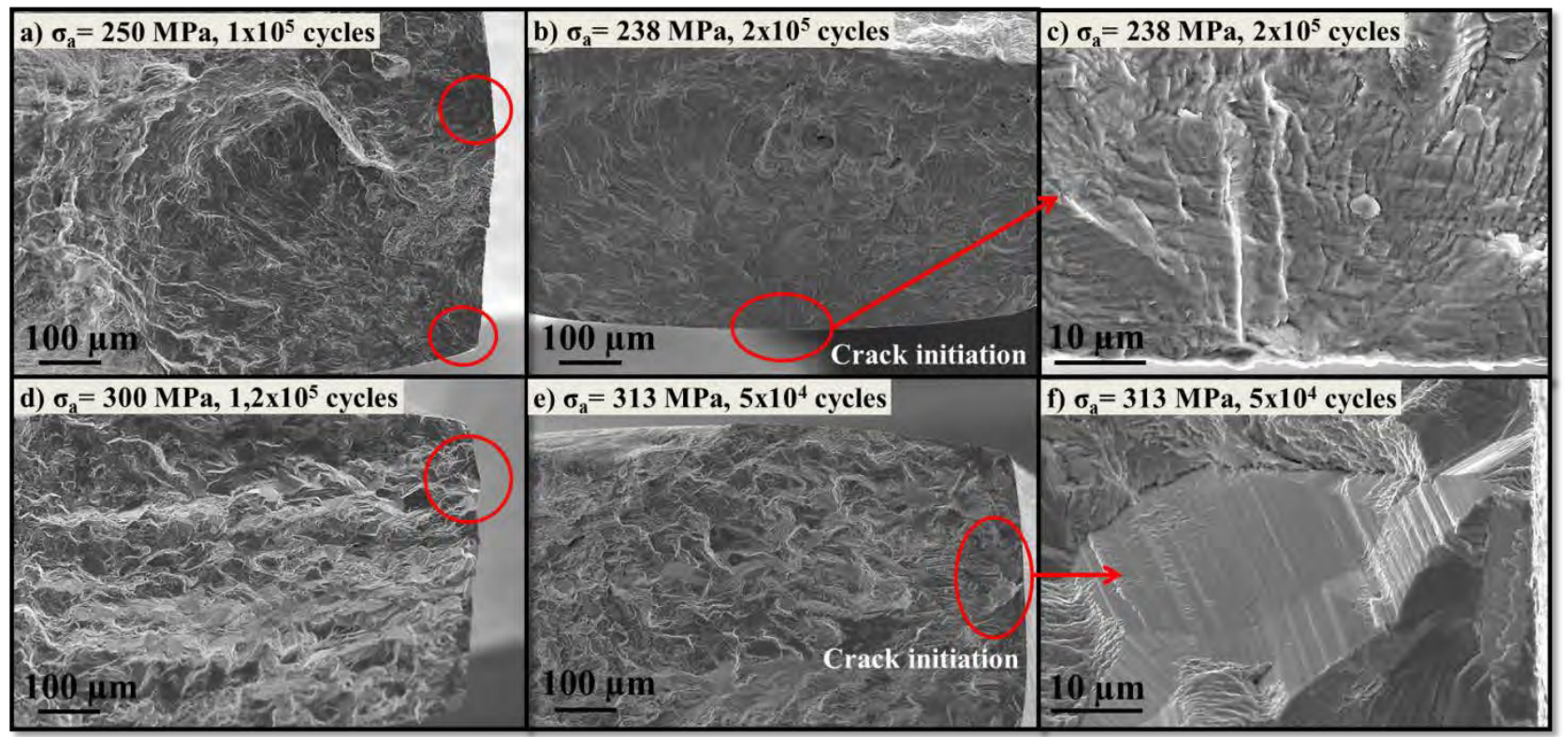

Fig. 7. Fracture surface analysis of Ti-40Nb alloy: (a-c) Ti-40Nb_Rk, (d-f) Ti-40Nb_Om4h

Comparing the studied binary Ti-Nb alloys with classical Ti-alloys such as Ti-6Al-4V, the cyclic strength of these renowned alloys cannot yet be reached.

However, in combination with its excellent biocompatibility and the very low Young's modulus the newly developed $(\beta)-\mathrm{Ti}-40 \mathrm{Nb}$ alloy, in particular in the aged condition, proves a high potential for future application as implant material [1].

\subsection{Fracture surface analysis}

All studied samples were subject of detailed fractographic analysis after the fatigue tests and all alloys and conditions show crack initiation at the surface. However, distinct differences in failure behaviour can be detected.

Fig. 7 depicts typical fracture surfaces of the $(\beta)$-Ti$40 \mathrm{Nb}$ alloy. The recrystallized condition (Ti- $40 \mathrm{Nb}$ Rk) shows transgranular cracks initiating from the sample surface. Higher stress amplitudes $\sigma_{\mathrm{a}}$ result in multiple crack initiation sites (Fig. 7a), whereas stress amplitudes below values of $250 \mathrm{MPa}$ lead to single crack initiation. A detailed inspection reveals ductile fatigue fracture characteristics with striations in the area of fatigue crack propagation, while dimples indicate the ductile nature of the material in the overload fracture area. Cracks are growing radially outgoing from the initiation site. A feathered and faceted structure can be identified in higher magnifications, which appears to be a sign for high amounts of stress-induced $\alpha$ "'-phase in this binary ß-titanium alloy.

Thus, the high instability of the $\beta$-phase at $40 \mathrm{wt} \%$ $\mathrm{Nb}$ seems to provide enough driving force to cause formation of localized $\alpha$ "-phase [31]. Whether this transformation is a result of the cyclic deformation or whether it was already present before fatigue testing has yet to be analyzed. In any case, the localized $\alpha$ "'-phase in the near surface region acts as potential crack initiation site.
Compared with the widely studied static deformation behaviour and the expectable mechanisms after the BoMd diagram, slip and twinning should be dominating for this alloy group [32]. Kim et al. [42] studied the effects of superelasticity and shape memory emerging from a $\mathrm{Nb}$-content of around $40 \mathrm{wt} \%$ and directly linked it with the double yielding behaviour and necessary minimal stresses below $200 \mathrm{MPa}$ for $\alpha$ "'-formation and reorientation. Hence, the cyclic stresses above this value in this study seem to initiate preferred transformation from $\beta$ to $\alpha$ " compared to deformation due to slip and twinning $[31,42]$.

Fracture surfaces of the aged condition with $\omega$ precipitations present in the $\beta$-matrix (Ti-40Nb_Om4h) are of intergranular appearance with cleavage structures instead of facets. This indicates a more brittle fatigue failure. The cleavage structures are more pronounced in the samples with high stress amplitudes $\sigma_{\mathrm{a}}$. While cracks initiate from the sample surface in all cases, no multiple crack initiation sites were observed irrespective of the stress amplitude.

Fatigue crack paths are in many cases not perpendicularly oriented to the applied stress but rather in 35 to 45 degree following preferred crystallographic planes according to Schmidt's law.

The more brittle nature of fatigue failure in the aged samples are in good agreement with the superior proof and ultimate tensile strength as well as decreased ductility (Table 2). Since superelasticity and shape memory effects are almost fully suppressed by the $\omega$ phase, cyclic deformation seems to be shifting towards dominating dislocation slip and possible twinning mechanisms. As a result initial crack formation (stage I) occurs along the plane of maximal shear stress [43].

The higher $\mathrm{Nb}$-content in the additionally studied $(\beta)$ $\mathrm{Ti}-45 \mathrm{Nb}$ alloy results in fracture surfaces as depicted in Fig. 8. Like both conditions of the $(\beta)-\mathrm{Ti}-40 \mathrm{Nb}$ alloy fatigue cracks always initiated at the surface of the samples. 
Higher magnification shows similar transgranular appearance compared to the fracture surface of the Ti$40 \mathrm{Nb}$ Rk samples with $\alpha$ ' '-phase formation. Following the phase stability approach according to the electronic parameters of the Bo-Md diagram the higher $\mathrm{Nb}$-content should inhibit stress-induced $\alpha$ "'-phase formation and cause deformation dominated by slip bands $[31,34]$.

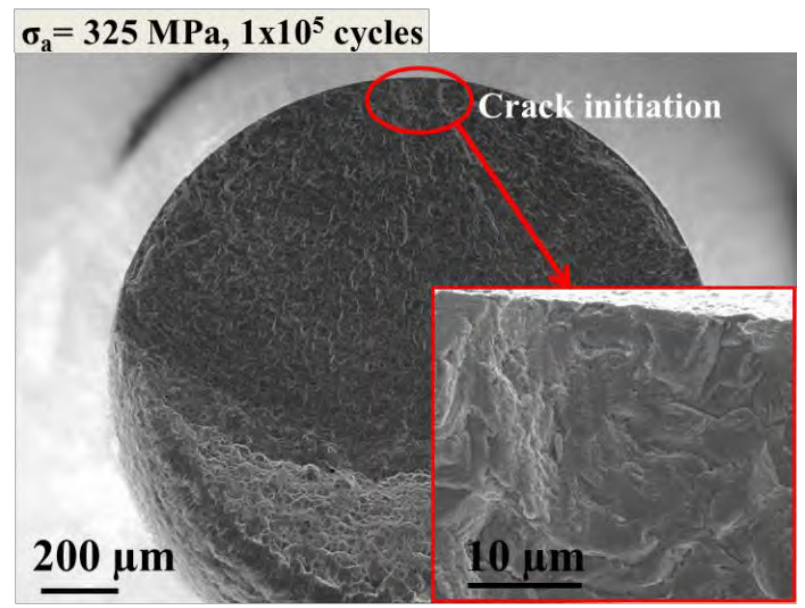

Fig. 8. Fracture surface analysis of Ti-45Nb alloy

Comparing the fracture surfaces, stress-induced $\alpha$ '”phase formation seems to be indeed an active cyclic deformation mechanism as well and must be subject of further investigations.

Regarding the influence of corrosion, no differences between the samples tested in air and in Ringer's solution are detectable, neither directly on the fracture surfaces nor at the radius area near the crack initiation site. This suggests that the natural forming oxide layer, which mainly consists of ductile $\mathrm{Nb}_{2} \mathrm{O}_{5}$ for Ti-Nb-based alloys instead of the more brittle $\mathrm{TiO}_{2}$ of e.g. cp-titanium or Ti$6 \mathrm{Al}-4 \mathrm{~V}$, is effective enough to resist early corrosion fatigue failure [13-14,41].

\section{Conclusions}

Focus of the current study was the fatigue behavior of two binary $(\beta)-\mathrm{Ti}-\mathrm{Nb}$ alloys and the influence of thermomechanical treatment as well as environment due to corrosion fatigue. A recrystallized and an aged condition with $\omega$-precipitations of a newly developed Ti$40(\mathrm{wt} \%) \mathrm{Nb}$ alloy were investigated and compared with results of industrial commercially available ( $\beta$ )-Ti$45(\mathrm{wt} \%) \mathrm{Nb}$ alloy. The findings can be summarized as follows:

(1) The fatigue strength at $2 \times 10^{6}$ cycles of the aged $\left(\sigma_{a}\right.$ $=288 \mathrm{MPa})$ and the recrystallized condition $\left(\sigma_{\mathrm{a}}=\right.$ $225 \mathrm{MPa})$ of the Ti-40Nb alloy differed significantly, caused by the contribution of precipitation hardening and the stabilizing character of the $\omega$-phase against $\alpha$ ' -phase formation.

(2) Aging of $\mathrm{Ti}-40 \mathrm{Nb}$ and the resulting less ductile deformation behaviour also became apparent in the fracture surfaces formed during fatigue loading. The recrystallized condition shows transgranular, more ductile failure perpendicular to the cyclic load direction, whereas the aged condition fails with a more brittle, intergranular characteristic alongside preferred crystallographic planes.

(3) The commercially available $(\beta)-\mathrm{Ti}-45 \mathrm{Nb}\left(\sigma_{\mathrm{a}}=300\right.$ $\mathrm{MPa})$ alloy showed slightly superior fatigue strength compared to the aged $(\beta)-\mathrm{Ti}-40 \mathrm{Nb}$ alloy. Irrespective of the higher $\beta$-phase stability from the higher $\mathrm{Nb}$-content, the fracture surface analysis revealed similar characteristics as the aged condition of $(\beta)$ $\mathrm{Ti}-40 \mathrm{Nb}$.

(4) No significant influence of corrosive environment on the fatigue strength could be observed during invitro testing, proving the excellent biocompatability of the tested binary $(\beta)-\mathrm{Ti}-\mathrm{Nb}$ alloy.

\section{Acknowledgement}

The authors gratefully acknowledge the work and contribution of S. Volkmann for conducting the tests on Ti- $45 \mathrm{Nb}$ and $\mathrm{M}$. Kuczyk for assistance in the analytical investigations. This project was funded by the Deutsche Forschungsgemeinschaft (DFG) in the framework of SFB/Transregio 79, project M1.

\section{References}

1. M. Niinomi, J. Mech. Behav. Biomed. Mater. 1 (1), 30-42, (2008)

2. M. Niinomi and M. Nakai, Int. J. Biomater., (2011), doi:10.1155/2011/836587

3. Q. Chen, G. A. Thouas, Mat. Sci. \& Eng.: R: Reports 87, 1-57, (2015)

4. M. Geetha, A. K. Singh, R. Asokamani, A. K. Gogia, Prog. Mat. Sci. 54 (3), 397-425, (2009)

5. M. Niinomi, Mat. Sci. \& Eng. A 243 (1-2), 231236, (1998)

6. M. Niinomi, Y. Liu, M. Nakai, H. Liu, H. Li, Regen. Biomater. 3 (3), 173-185, (2016)

7. T. Ozaki, H. Matsumoto, S. Watanabe, S. Hanada, Mater. Trans. 45 (8), 2776 - 2779, (2004)

8. M. Long, H. Rack, Biomater. 19 (18), 1621-1639, (1998)

9. I. Jimenez-Palomar, A. Shipov, R. Shahar, A. H. Barber, Front. Mater. 2 (9), 1-13, (2015)

10. M. Abdel-Hady Gepreel, M. Niinomi, J. Mech. Behav. Biomed. Mater. 20, 407-415, (2013)

11. C. Fleck, D. Eifler, Int. J. Fatigue 32 (6), 929-935, (2010)

12. R. A. Antunes, M. C. Lopes de Oliveira, Acta Biomater. 8 (3), 937-962, (2012)

13. R. Godley, D. Starosvetsky, I. Gotman, J. Mat. Sci. 17, 63-67, (2006) 
14. F. Rubitschek, T. Niendorf, I. Karaman, H. J. Maier, J. Mech. Behav. Biomed. Mater. 5 (1), 181-192, (2012)

15. M. Marteleur, F. Sun, T. Gloriant, P. Vermaut, P. J. Jacques, F. Prima, Scri. Mater. 66 (10), 749-752, (2012)

16. A. Helth, S. Pilz, T. Kirsten, L. Giebeler, J. Freudenberger, M. Calin, J. Eckert, A. Gebert, J. Mech. Behav. Biomed. Mater. 65, 137-150, (2017)

17. S. Bahl, S. Das, S. Suwas, K. Chatterjee, J. Mech. Behav. Biomed. Mater. 78, 124-133, (2018)

18. S. Guo, J. Zhang, X. Cheng, X. Zhao, J. Alloys \& Comp. 644, 411-415, (2015)

19. S. Hanada, N. Masahashi, T. K. Jung, M. Miyake, Y. S. Sato, H. Kokawa, J. Mech. Behav. Biomed. Mater. 32, 310-320, (2014)

20. C. Huang, Y. Zhao, S. Xin, C. Tan, W. Zhou, Q. Li, W. Zeng, Int. J. Fatigue 94, 30-40, (2017)

21. C. Lan, Y. Wu, L. Guo, F. Chen, Mat. Sci \& Eng.: A 690, 170-176, (2017)

22. K. Ozaltin, W. Chrominski, M. Kulczyk, A. Panigrahi, J. Horky, M. Zehetbauer, M. Lewandowska, J. Mater. Sci. 49 (20), 6930-6936, (2014)

23. S. Ozan, J. Lin, Y. Li, Y. Zhang, K. Munir, H. Jiang, C. Wen, J. Mech. Behav. Biomed. Mater. 78, 224234, (2017)

24. J. Stráský, P. Harcuba, K. Václavová, K. Horváth, M. Landa, O. Srba, M. Janeček, J. Mech. Behav. Biomed. Mater. 71, 329-336, (2017)

25. P. Majumdar, S. B. Singh, S. Dhara, M. Chakraborty, J. Mech. Behav. Biomed. Mater. 10, 1-12, (2012)

26. K. Cho, M. Niinomi, M. Nakai, J. Hieda, R. Kanekiyo, Mater. Trans. 54 (10), 2000-2006, (2013)

27. H. Liu, M. Niinomi, M. Nakai, S. Obara, H. Fujii, Mat. Sci. \& Eng.: A 704, 10-17, (2017)

28. X. Song, M. Niinomi, M. Nakai, H. Tsutsumi, L. Wang, Mat. Sci. \& Eng.: C 32 (3), 542-549, (2012)

29. X. Song, L. Wang, M. Niinomi, M. Nakai, Y. Liu, Mat. Sci. \& Eng.: A 640, 154-164, (2015)

30. M. Nakai, M. Niinomi, T. Oneda, Metall. \& Mat. Trans. A 43 (1), 294-302, (2012)

31. M. Abdel-Hady, K. Hinoshita, M. Morinaga, Scri. Mater. 55 (5), 477-480, (2006)

32. D. Kent, G. Wang, M. Dargusch, J. Mech. Behav. Biomed. Mater 28, 15-25, (2013)

33. M.J. Lai, C.C. Tasan, D. Raabe, Act. Mater. 100, 290-300, (2015)

34. M. Morinaga, N. Yukawa, T. Maya, K. Sone, H. Adachi, Proc. 6th World Conf. Titan., France, 1601-1606 (1988)

35. J.J. Gutiérrez Moreno, M. Bönisch, N. T. Panagiotopoulos, M. Calin, D. G. Papageorgiou, A. Gebert, J. Eckert, G. A. Evangelakis, C. Lekka, J. Alloys \& Comp. 696, 481-489, (2017)
36. A. Reck, S. Pilz, M. Calin, A. Gebert, M. Zimmermann, Int. J. Fatigue 103, 147-156, (2017)

37. T. Furuhara, T. Maki, T. Makino: J. Mater. Process. Technol. 117, 318-23, (2001)

38. M. Delshadmanesh, G. Khatibi, M. Lederer, M. Zehetbauer, H. Danninger, SSP 258, 337-340, (2016)

39. Company Certificate ATI $45 \mathrm{Nb}^{\mathrm{TM}}$ Alloy, Allegheny Technologies Incorporated (ATI), Batch-No.TSC522069

40. S. Shin, C. Zhang, K.S. Vecchio, Mat. Sci. \& Eng.: A 702, 173-183, (2017)

41. P.F. Gostin, A. Helth, A. Voss, R. Sueptitz, M. Calin, J. Eckert, A. Gebert, J. Biomed. Mater. Res. 101B, 269-278, (2013)

42. H.Y. Kim, S. Hashimoto, J. I. Kim, H. Hosoda, S. Miyazaki, Mater. Trans. 45 (7), 2443-2448, (2004)

43. S.A. Mantri, D. Choudhuri, T. Alam, V. Ageh, F. Sun, F. Prima, R. Banerjee, Scri. Mater. 130, 69-73, (2017) 